\title{
MERCADO CENTRAL DE CAJAZEIRAS-PB: DIRETRIZES DE REABILITAÇÃO PARA RESGATE DA VITALIDADE DO ESPAÇO
}

\author{
CAJAZEIRAS-PB CENTRAL MARKET: SPACE VITALITY \\ REHABILITATION GUIDELINES
}

\author{
Glaucia Pinto de Sousa ${ }^{1}$ \\ Pollyanna Priscila de Souza Lima² \\ Isabel Sobral de Abreu e Lima $^{3}$ \\ André Ferreira Costa ${ }^{4}$ \\ Camilla Furtado de Figueiredo ${ }^{5}$ \\ Janderson Ferreira Dutra ${ }^{6}$
}

RESUMO: Os mercados públicos, desde os primórdios, assumem papel fundamental na gênese e progresso citadino. Implantados principalmente nos centros históricos são equipamentos urbanos centralizadores e determinantes na configuração espacial urbana e no desenvolvimento econômico com geração de emprego e renda. Considerando essa importância história, cultural, social e econômica do setor terciário com foco nas atividades varejistas, Cajazeiras-PB traz em seu repertório o Mercado Central, um marco histórico e evolutivo das feiras livres que foi construído no ano de 1951. Quando edificado, e décadas posteriores, esse mercado era de grande popularidade e reconhecimento com diversidade ampla de produtos, serviços e fomento das relações socioculturais locais. No entanto, diante do progresso urbano e considerando a situação atual, tornou-se uma centralidade despercebida, pouco significativa e em condições desfavoráveis. Dessa forma, para compreensão do cenário atual do ambiente edificado, aplicou-se uma pesquisa de caráter científico, com metodologia de natureza aplicada e abordagem qualitativa, embasada na percepção de protagonistas do próprio mercado, atrelada a exploração e sistematização dos dados e, expressos através da análise SWOT com objetivo de apresentar diretrizes de reabilitação para resgatar a vitalidade do espaço. Em lógica decorrência, as diretrizes de reabilitação aqui apresentadas

\footnotetext{
${ }^{1}$ Graduada em Arquitetura e Urbanismo pela Faculdade Santa Maria, Cajazeiras, Paraíba.

2 Docente da Faculdade Santa Maria, Cajazeiras, Paraíba.

${ }^{3}$ Docente da Faculdade Santa Maria, Cajazeiras, Paraíba.

4 Docente da Faculdade Santa Maria, Cajazeiras, Paraíba.

5 Docente da Faculdade Santa Maria, Cajazeiras, Paraíba.

${ }^{6}$ Docente da Faculdade Santa Maria, Cajazeiras, Paraíba.
} 
compreenderam e respeitaram o setor terciário no contexto urbano, entorno imediato, legislações pertinentes e necessidades dos usuários, sejam eles assíduos ou esporádicos, com estratégias aplicáveis e satisfatórias para reavivar a funcionalidade do Mercado Central, bem como conceber um ambiente aprazível aos seus utentes ensejando, assim, posterior desenvolvimento projetual.

DECSRITORES: Mercado público, Mercado Central, Vitalidade, Reabilitação, Diretrizes.

ABSTRACT: Since the earliest times, public markets have played a key role in the formation and progress of a city. Located in historical downtown, they are centralizing urban elements that determine the urban spatial configuration and the economic development with generation of employment and income. Considering this historical, cultural, social and economic importance of the tertiary sector focused on retail activities, The Mercado Central bring to Cajazeiras- $P B$ a historical and evolutionary street market's landmark since its construction in 1951. When it was built, and decades later, this market was very popular and had great recognition because of wide diversity of products, services and fostering of local socio-cultural relations. However, in the face of urban progress and considering the current situation, it has become an unnoticed, insignificant and unfavorable center. In order to understand the current scenario, a research of a scientific nature, applied methodology and a qualitative approach based on the perception of the market participants was applied linked to the exploration and systematization of data presented through SWOT analysis with objective to present rehabilitation guidelines to rescue the vitality of space. Thus, the rehabilitation guidelines presented included the tertiary sector in the urban context, immediate surroundings, pertinent legislations and needs of regular or sporadic users, with applicable and satisfactory strategies to revive Central Market functionality, as well as having a pleasant environment for its users thus leading to subsequent design development.

DESCRIPTORS: Public Market, Mercado Central, Vitality, Rehabilitation, Guideline. 


\section{INTRODUÇÃO}

A cidade de Cajazeiras, com mais de um século e meio de emancipação política, abriga um contexto histórico simbólico ancorado na educação, religião e comércio, como manifesta Silva (2014, p. 23), ao afirmar que "o início da ocupação remota de meados do século XIX desenvolvendo-se a partir de uma fazenda à sombra de uma igreja, de um açude e de uma escola".

Nesse sentido, considerando o panorama evolutivo do progresso, o comércio assume papel fundamental no desenvolvimento econômico, social e cultural bem como na expansão urbana, relação de dependência desde a gênese das cidades e que, para poucas exceções não assumiam esse elo. Conforme Vargas (2018, p. 4), "existe, portanto, uma relação umbilical entre comércio e as demais atividades sócias, que raras vezes foi rompida". Assim sendo, para que tais atividades alcancem reconhecimento e popularidade, faz-se necessário que esses pontos sejam fixados em locais estratégicos visando à otimização de tempo e deslocamento para tornarem-se mais acessíveis ao público em geral.

Destarte, considerando esse empulsionamento dado pelo setor comercial, desde as primeiras manifestações dos núcleos urbanos, Cajazeiras, não diferentemente de tantas outras urbes, carrega em seu seio essa relação de dependência e consolidação impulsionada pelo setor comerciário, com destaque nas atividades terciárias e atuação dos indivíduos, sejam eles fornecedores ou consumidores.

Nessa linha de abordagem, a referida cidade agrega uma grande diversidade de comércio tornando-se polo, acolhendo e atendendo as necessidades de oferta e de procura por parte da população da região e estados circunvizinhos.

Em lógica decorrência, o contexto histórico evolutivo relacionado à temática do comércio local, abriga em sua memória características singulares e marcantes desde as primeiras feiras livres a céu aberto - também existentes nos dias atuais até o mercado edificado, que assume caráter de elemento urbano centralizador e 
que delineia a identidade da cidade, como defende Nabil Bonduki (2015. p. 146), ao afirmar que "cada cidade tem um mercado característico, com produtos específicos, diferentes formas de apresentá-los e uma oferta variada de sensações que lhe dão uma vida própria", no caso para a presente pesquisa, identificado como o Mercado Central, infelizmente hoje não mais apresentável, aprazível e com a mesma vitalidade de décadas anteriores.

Assim sendo, diante das abordagens anteriores e direcionadas para o Mercado Central de Cajazeiras, esse trabalho é ancorado no pouco reconhecimento e valoração dessas atividades terciárias expressas nas palavras de (VARGAS, 2018).

No entanto, apesar de toda essa importância social e econômica implícita, a atividade de troca - não apenas de produtos, mas também de serviços - carregou, por milênios, o estigma de atividade indigna, desprezível e de pouco significado para o desenvolvimento econômico e social (VARGAS, 2018, p.4).

Ainda em caráter complementar a essa problemática em âmbito local, considerando sua funcionalidade e vitalidade, a concorrência com estabelecimentos mais sofisticados e estruturados é um condicionante crítico que restringe e minimiza a procura por esse espaço terciário - Mercado Central - pois não dispõem de estrutura física e funcional adequada, condições de comodidade e segurança bem como oferta diversificada e suficiente para atender as necessidades dos clientes e tão pouco despertar o interesse de eventuais visitantes. Dito isto, a presente pesquisa tem por objetivo geral apresentar diretrizes de reabilitação urbana para resgate da vitalidade do Mercado Central de Cajazeiras - PB.

Para alcançar esse objetivo com êxito, fez-se necessário compreender algumas singularidades do espaço edificado e de seus protagonistas tirando partido dos objetivos específicos: compreender a logística e funcionamento do estabelecimento, bem como as necessidades de melhoria do espaço edificado; analisar normativas considerando parâmetros construtivos, patrimônio histórico, segurança, acessibilidade, conforto ambiental, salubridade; propor novas ofertas de produtos e serviços, tais como, itens de artesanato local, produtos de culinária regional e setores de alimentação de forma que atenda às necessidades do consumidor favorecendo a vitalidade ao espaço e, contribuir com discursões e incitar 
reflexões dos espaços públicos, bem como incentivar a valorização das relações econômicas, históricas e sociais locais através do mercado que é um equipamento de articulação urbana.

Diante dessas condições e embasados nas considerações de Vargas (2018, p.253), ao comprovar que "o varejista tem de procurar manter a sua boa imagem, não apenas em termos dessa imagem mental, mas também pelas características físicas do estabelecimento", a abordagem do tema se justifica na necessidade de uma estratégia urbana que reabilite o estabelecimento comercial edificado, valorizando e respeitando as potencialidades econômicas, históricas e sociais de forma que fomente a procura do comércio desse setor terciário, trazendo vitalidade ao espaço edificado e ativação do entorno imediato.

Em caráter de hipóteses, Vergana (2011, p. 28) afirma que "Hipóteses, ou suposições, são a antecipação da resposta ao problema". Em relação às hipóteses, estas estão associadas investigações, quase sempre, via procedimentos estatísticos e, as suposições voltadas mais para pesquisas qualitativas, via mecanismos não estatísticos. No entanto, a presente pesquisa por assumir caráter exploratório "não admitem formulações de hipóteses, nem a de suposições, embora se admita que, na prática, alguma intuição se tenha a respeito da resposta ao problema" (VERGANA, 2011, p. 29).

Assim sendo, as afirmações ou refusões acerca dos pontos positivos e problemáticas do espaço edificado surgiram ao longo de toda a análise e foram expressos em forma de diagnóstico que, posteriormente, apresentou-se as diretrizes direcionadas para resgate da vitalidade do espaço, isso uma vez que, "o terciário está aí, cada vez mais presente, dominando nossas cidades, criando e resolvendo problemas" (VARGAS, 2018, p. 17).

\section{MÉTODO}

Trata-se de um estudo qualitativo e aplicado que, de acordo com André (1983, p. 66) essa abordagem visa a "apreender o caráter complexo e 
multidimensional dos fenômenos em sua manifestação natural" bem como capturar os diferentes significados das experiências vividas auxiliando a compreensão fiel do comportamento do indivíduo no seu espaço.

A coleta foi realizada no Mercado Central de Cajazeiras, Paraíba, edificado e ativo há 68 destinado a atividades de comércio e serviço. A referida pesquisa foi desenvolvida entre agosto de 2018 a maio de 2019.

Foi embasada em pesquisas bibliográficas e documentais com temas recorrentes com aplicação de entrevistas abertas e questionário semiestruturado para, posterior estudo e descrição comprovando a situação-problema do mercado e formulação das diretrizes projetuais.

Os instrumentos foram destinados a dois funcionários e dois clientes do estabelecimento que responderam aos questionários livres a posicionamentos e colocações complementares aos pré-estabelidos. Bem como entrevista com historiador local relatando a importância do mercado para o contexto histórico, cultural e político de Cajazeiraspara isso foram aplicados cinco métodos: aporte teórico, observação do pesquisador, registro fotográfico, aferição de algumas medidas pontuais e coleta documental pertinente ao objeto.

A aplicação da entrevista aberta, que também fez- se necessário a apresentação do TCLE, a mesma foi aplicada dia 14 de maio do corrente ano. A entrevista seguiu um roteiro pré-estabelecido estando o entrevistado livre para considerações e posicionamentos em relação ao tema abordado, até porque ele detém um profundo conhecimento do objeto de estudo, tanto da situação atual como de décadas transcorridas onde ele vivenciou e ainda vivencia o funcionamento do equipamento urbano em questão. Em suma, a entrevista teve por objetivo analisar as características do Mercado Central da cidade de Cajazeiras- PB, bem como a importância desse estabelecimento no contexto urbano para a cidade e região. 


\section{RESULTADOS E DISCUSSÃO}

As presentes abordagens correspondem a percepções do espaço edificado, sejam elas transcorridas ou vivenciadas nos dias atuais, por parte dos seus reais protagonistas considerando termos funcionais, culturais, sociais e econômicos bem como do leque de novas possibilidades e singularidades que pode ser concebido ao mercado e seus utentes.

Os questionários foram aplicados dia 11 de maio do corrente ano, ou seja, em um sábado pela manhã, visto que esse seria o momento de maior contingente de clientes no mercado, como assim é em todo o centro comercial. No entanto, essa lógica não procedeu sendo constatado e afirmado por funcionários que o sábado é o dia de menos movimentação. Essa situação pode ser justificada pela concentração de feiras livres em grande extensão do centro comercial nos dias de sábado, aumentando assim a concorrência ao Mercado Central.

Os questionários aplicados aos clientes foram abordados um homem, e uma mulher, identificados como A e B respectivamente, com idades entre 21 e 40 anos. Ao questionar a periodicidade que frequentavam o mercado, ambos afirmaram que não era estabelecida, no entanto, a mulher afirma ser mais de uma vez ao mês. Ambos os sujeitos da pesquisa frequentam o espaço há mais de 10 (dez) anos buscando principalmente calçados e vestuário. Considerando a situação na qual o mercado se encontra e as principais necessidades de melhorias, as respostas foram coincidentes: higiene, infraestrutura e segurança. Nesse quesito de melhorias, o sujeito B propôs uma "nova roupagem" ao estabelecimento. No tocante às possibilidades de inserção de oferta de novos produtos, bem como serviços, foi sugerida pelo sujeito $A$ uma praça de alimentação, até porque o único ponto de lanches existente é bem elementar e pequeno e, novas variedades de produtos.

Considerando os questionários para os funcionários, identificados como $\mathrm{C} \mathrm{e}$ D, ambos foram do sexo masculino, com idade superior a 31 anos e horário de trabalho em período vespertino, das $7: 30 \mathrm{~h}$ as $17: 00 \mathrm{~h}$ com pausa pra almoço. $O$ tempo de trabalho dentro do mercado é muito relativo. Na visão dos mesmos, o 
público que mais frequenta o espaço é jovem e mulheres e buscam produtos de aviamentos e calçados do tipo tênis e rasteirinhas e, ao serem questionados sobre as principais necessidades de melhorias diante da situação atual, afirmaram que a estrutura e a estética e modernização do espaço.

Como constatado, o Mercado Central assume papel fundamental para os protagonistas daquele espaço e essa afirmativa é comprovada quando questionado qual a importância do mesmo. Do ponto de vista para ambos os sujeitos, funcionários e clientes, o mercado é importante por ofertar uma diversidade ampla, principalmente de produtos, por atender as classes mais inferiores, por ser um elemento social e gerador de emprego e renda familiar, onde muitas famílias tem total dependência financeira. No entanto, necessita de melhorias para ter mais visibilidade, onde eles atribuíram ser um dos grandes problemas a questão de o espaço ser muito fechado e, novamente pontuam a inserção de uma praça de alimentação para atrair uma maior procura e satisfação do espaço.

A caráter de identificação, o historiador entrevistado, identificado como sujeito E, com idade de 70 anos, licenciado em História com Especialização em História da América e experiência profissional como Professor universitário e radialista, o qual foi convidado a relatar um pouco do seu conhecimento a respeito do mercado.

Considerando o questionamento em relação à representatividade e importância do Mercado Central para a cidade e região fundamentado no processo evolutivo urbano dentro dos contextos histórico, cultural, social e econômico, o historiador declara que "do ponto de vista histórico e cultural o mercado público é uma marca importante na vida de todas as cidades" e que toda cidade, independentemente do tamanho tem um mercado público e este assumia diversas funções.

A gente conhece muitas cidades aqui da região, e a gente sabe que toda cidade por maior ou menor que ela seja tem um espaço chamado de mercado público que é utilizado comercialmente, é claro, mas que muitas vezes serviu também de local de festas, local de congraçamento e principalmente quando as cidades não dispunham de um clube, um clube social. Então, era no mercado público que durante o dia servia de comércio e nos finais de semana, nos dias excepcionais era utilizado 
também para festas, para bailes e etc... Então, historicamente o mercado tem um papel importante porque ele é um ponto de convergência não só dos comerciantes, mas também de toda a população da cidade e da região.

Para as relações econômicas e sociais, o mercado era "o ponto de fomento das atividades econômicas do município, afinal de contas nem todo mundo tinha a oportunidade de ter um prédio comercial próprio, então era utilizado o mercado público" sendo também um local de encontro e de "trocas de pontos de vistas, discutiam os assuntos da cidade, a política a religião enfim, era um espaço social de encontro da população". O referido espaço se destacava mais ainda em datas festivas.

Eu me lembro que nos anos 60 e 70 o mercado recebia um fluxo de pessoas muito grande. As vezes concentrava ali um comércio que era muito pujante, um comércio muito forte. Eu me lembro também do mercado público em determinadas festas de Natal o mercado abria, era uma concentração muito grande de pessoas. (E. 2019).

O entrevistado prossegue e menciona a fundação do mercado ter sido na gestão do prefeito Arsênio Araruna e sua localização central, como já relatado anteriormente. No entanto, também deixa bem claro a situação atual do estabelecimento em seu aspecto físico ao afirmar que "hoje como ele está realmente é uma tristeza e nem sei como aqueles pequenos comerciantes continuam resistindo a concorrência que eles sofrem do comércio de Cajazeiras fora do mercado" (C.A, 2019). Em complementariedade, suas palavras detalham com mais precisão o estado no qual o mercado se encontra.

Então, é um espaço realmente muito grande, agora vivendo um momento de decadência, diria eu. Hoje, se a gente for no mercado público nós vamos encontrar muitos espaços vazios, muitos espaços fechados, muitos locais de lojas abandonados, na verdade serve de deposito para muitos comerciantes que lá continuam. As lojas, necessitando urgentemente de uma melhora [...] prédio está com suas instalações físicas em estado, eu diria que deploráveis, o serviço de 
energia e abastecimento de água também precisam ser melhorados, enfim ele precisa ser revitalizado. (E. 2019).

Considerando a oferta atual do mercado, "ele tem aí no momento uma oferta de muitos produtos: de calçados, de vestimentas, sobretudo a vestimenta infantil, aviamentos, linhas, botões e roupinhas para batizados e aniversários de crianças" (E. 2019). Para as possibilidades de melhorias com inserção ou exclusão de ofertas presentes a fim de resgatar a vitalidade do espaço, poderia existir "a praça de alimentação para que pudesse resgatar, quem sabe, a gastronomia regional e evidentemente naquele espaço mantido alguma coisa já construída, mas também poderia construir uns dois ou três pavimentos" (E. 2019).

Ao final da entrevista foram feitos os agradecimentos em relação à atenção e a gentileza do entrevistado, que deixou suas últimas considerações e, nesse momento foi enfatizada a importância da atuação da Secretária da Cultura.

Eu acho que poderia ser pensado também num trabalho conjunto com a Secretária da Cultura para, em havendo essa revitalização, a Secretária de Cultura ter um papel mais presente ali dentro do mercado e muita coisa no ponto de vista cultural que o mercado poderia receber (E. 2019).

Nesta perspectiva, a aplicação da entrevista aberta comprovou e enriqueceu diversas afirmações já elencadas, tendo esta, papel fundamental corroborando e ampliando essas percepções do próprio protagonista do espaço dentro de vários pontos específicos.

Inserida na região Nordeste, mas especificamente no extremo Oeste do estado da Paraíba, Cajazeiras está circunscrita em uma localização estratégica que permite relação com diversos municípios circunvizinhos bem como de outro estado, nesse caso, do Ceará. Desta forma, mesmo sendo considerada uma cidade relativamente pequena, segundo IBGE (2017), com população estimada de 61 mil habitantes e extensão territorial de 565,899 quilômetros quadrados, Cajazeiras teve seu processo de urbanização bem mais acelerado que seus municípios vizinhos permanecendo em contínuo desenvolvimento, assumindo assim, configuração de 
cidade polo exercendo grande influência para o seu entrono e atendendo a população recorrente.

$\mathrm{Na}$ época de sua inauguração, o mercado de Cajazeira, foi um marco para o desenvolvimento da cidade, "a mais importante das obras realizadas em seu quadriênio governamental foi a construção do Mercado Público, um prédio moderno para época, que despertou de toda a cidade os mais francos elogios" (SILVA, 2014, p. 119), e era comtemplado com uma diversidade ampla de produtos e serviços, tais como: roupa, caçados, setores de alimentação, cabeleireiro, frutas, artesanato local, aviamentos, diversas miudezas e comidas típicas como o caldo de cana, dentre tantos outros que será retratado em capítulos sucessivos. No entanto, os registros digitais, bem como tantas outras formas de documentação histórica relacionadas as décadas iniciais da construção e efervescência são raríssimos, mas ainda encontram-se algumas fotos de ocasiões excepcionais, como é o caso de uma carreata que apresentava os últimos modelos de Aero-Willys e Jeeps na década de 1960 e outras foto, relíquias cedidas, generosamente, por um historiador local que é detentor de um extenso e riquíssimo acervo fotográfico, fruto do seu trabalho de décadas e que hoje resguarda parte da história e da memória da cidade de Cajazeiras.

Vale considerar que o estabelecimento é pertencente à Prefeitura Municipal. No entanto, sob o termo de Comodato de 26 de julho de 1999, válido por 20 anos, o prédio encontra-se sob a administração da Associação dos Comerciantes do Mercado. No âmbito dessa autorização, os usuários do espaço mantêm seus comércios isentos de taxa de aluguel, mas com responsabilidade de preservar 0 imóvel podendo ser executados reforma de melhoria, controlar os espaços interno e tamanhos das barracas sem modificação do uso, sendo este exclusivo para pequeno comércio dentre outras especificações. Em relação à fiscalização de higiene e segurança, cabe ao comodante, ou seja, a Prefeitura Municipal (TERMO DE COMODATO, 1999, p.1-2).

Em relação a sua implantação, como mencionado, o mesmo está inserido em um ponto estratégico, no centro da cidade, caracterizado por uma área com predominância comercial na qual se concentra intenso fluxo de automóveis e pessoas. No entanto, tornou-se uma centralidade encapsulada, diferentemente dos 
tempos transcorridos, que dispunha de diversas entradas que davam acesso às vias e algumas destas, por vezes, davam continuidade, a céu aberto, ao comércio amplo e dinâmico do entorno imediato.

Em caráter conclusivo no âmbito das explanações da caracterização e descrição do mercado, evidenciou-se que os boxes de venda e serviços são dispostos de forma simétrica, no entanto verificou-se que em alguns locais pontuais esses mesmo estão bem próximos comprometendo a circulação das pessoas. Considerando a estrutura, é de uma diversidade de materiais: drywall, alvenaria, madeira, estrutura modulada em aço e que vários desses encontram-se desocupados, condição esta que impacta negativamente na agradabilidade do espaço, principalmente em questões de estéticas.

Apesar das condições reais do mercado, ele encontra-se resistindo ao tempo e a concorrência permanecendo aberto ao público e ao consumidor, necessitando urgentemente de melhorias para recuperação da sua vivacidade.

\section{CONSIDERAÇÕES FINAIS}

Perante as atividades de trocas, sejam elas comerciais ou sociais manifestadas desde os primeiros núcleos urbanos e, especialmente para aquelas concebidas em espaços terciários, o mercado público surge como equipamento urbano centralizador que compreende em seu contexto urbano um repertório histórico, cultural, social e econômico significativo e impulsionador do comércio local que requer valoração e investimentos públicos, em especial para aqueles espaços edificados que encontram-se em situação de decadência.

Nesse sentido, trazendo para escala local, o mercado público de Cajazeiras, conhecido por Mercado Central vivencia o referido cenário necessitando de intervenções urbanas que concebam um ambiente aprazível e convidativo. Nessa concepção, a proposta aqui abordada correspondeu a estratégia de reabilitação consistindo em análises e sínteses das necessidades dos utentes prezando por 
critérios de estética e funcionalidade para, a partir dessas ter sido apresentadas as diretrizes para resgate da vitalidade do espaço.

Destarte, é inegável que dificuldades existiram nas análises aqui expressas pois, raramente encontra-se registros sobre o estabelecimento e, partindo para a percepção dos protagonistas do espaço, poucos aceitam contribuir com seus pontos de vista, visto que muitos têm receio em exprimir determinadas situações insatisfatórias do estabelecimento.

Todavia, mesmo diante de tais dificuldades, os objetivos propostos foram atingidos, pois a extensa pesquisa comprovou que as estratégias de reabilitação aqui apresentadas são coerentes e aplicáveis para posterior desenvolvimento projetual com resultados satisfatórios promovendo maior dinamismo das relações econômicas e resgate da vitalidade do espaço.

Em caráter conclusivo, as atividades terciárias, principalmente por nem sempre terem o reconhecimento atinente a sua real representatividade, sendo um equipamento urbano que conecta seus utentes fornece-Ihes uma diversidade de produtos e serviços, que assegura emprego e renda para inúmeras famílias, que expressa a cultura local bem como dinamismo social, necessitam de um olhar mais direcionado e ações mais ativas que prezem por continuidade de seus usos e suas funções. Essa carência é bem expressiva quando direcionada ao Mercado Central de Cajazeiras que se encontra em decadência e vive um momento de incerteza perante o término do prazo do termo de comodato. No entanto, que as atuações públicas vindouras reconheçam e valorizem a "essência" dessas atividades terciárias e torne esse espaço cada vez mais aprazível e propagador dessas relações de troca.

\section{REFERÊNCIAS BIBLIOGRÁFICAS}

ABREU, Maurício de Almeida. Sobre a memória das cidades. Revista da Faculdade de Letras, Porto, p.77-97, 30 out. 2018.

ANDRÉ, Marli Eliza Dalmazo Afonso de. Cadernos de Pesquisa: exto, contexto e significado: algumas questões na análise de dados qualitativos. 1983. Disponível em: http://publicacoes.fcc.org.br/ojs/index.php/cp/article/view/1491/1485. Acesso em: 18 maio 2019. p. 66. 
ARCHEA ASSOCIATI (Florença). Mercado de San Lorenzo. 2014. Disponível em: https://www.archea.it/pt-br/mercato-san-lorenzo/. Acesso em: 28 abr. 2019.

ASSOCIAÇÃO BRASILEIRA DE NORMAS TÉCNICAS. ABNT NBR 9050: Acessibilidade a edificações, mobiliário, espaços e equipamentos urbanos. Rio de Janeiro, 2015.

BETONI, Simone. O Mercado central de Florença. 2015. Disponível em: https://www.oguiademilao.com/o-mercado-central-de-florenca/. Acesso em: 28 abr. 2019.

Brasil. Ministério das Cidades/ Agência Espanhola de Cooperação Internacional- AECI. Manual de Reabilitação de Áreas Urbanas Centrais / Coordenação Geral de Renato Balbim Brasília: Ministério das Cidades; Agência Espanhola de Cooperação Internacional - AECI, 2008.

BONDUKI, Nabil (Org.). Intervenções Urbanas na Recuperação de Centros Históricos: Reabilitando Mercados sem matar sua alma. 2015. Disponível em: http://portal.iphan.gov.br/uploads/publicacao/ColArq3_Intervencoes_Urbanas_na_Recuperac ao_de_Centros_Historicos_m.pdf. Acesso em: 20 out. 2018.

BROERING, Zulian; FIGUEIREDO, Zanatta. Primeiro Lugar no Concurso para a Requalificação do Mercado Público de Lages-SC. 2014. Disponível em: https://www.archdaily.com.br/br/755352/primeiro-lugar-no-concurso-para-a-requalificacao- domercado-publico-de-lages-sc-zulian-broering-plus-zanatta-figueiredo. Acesso em: 27 abr. 2019.

BETONI, Simone. O Mercado central de Florença. 2015. Disponível em: https://www.oguiademilao.com/o-mercado-central-de-florenca/. Acesso em: 28 abr. 2019.

COSTA, Antonio Assis. A(s) Cajazeiras que eu vi e onde vivi. João Pessoa: Gráfica Progresso - Ltda, 1986. $179 \mathrm{p}$.

COOPCENTRAL. Mercado Central de Fortaleza: História. 2017. Disponível em: https://www.mercadocentraldefortaleza.com.br/historia/. Acesso em: 15 maio 2019.

Entrevista. [mai. 2019]. Entrevistador: Glaucia Pinto de Souza. Cajazeiras, 2019. O roteiro da entrevista encontra-se no Apêndice I deste Trabalho de Conclusão de Curso. 